\title{
Utilização de jogos educativos como recurso no processo de ensino de ciências abordando tópicos de astrofísica
}

\author{
Aline Mariana Stiz ${ }^{1}$, Ricardo de Sousa Costa ${ }^{2}$ \\ 1,2 Universidade Federal de Rondônia (UNIR)
}

Palavras-Chave: Ensino de Física, Jogos educativos, Aprendizagem significativa, Astrofísica.

\section{Introdução}

De acordo com os PCNEM (Parâmetros Curriculares Nacionais do Ensino Médio), Parte III - Ciências da Natureza, Matemática e suas Tecnologias, o ensino de Física tem-se realizado mediante a apresentação de conceitos, leis e fórmulas, de forma desarticulada, sem uma correlação com o dia a dia dos alunos e professores, tornando o conhecimento sem importância, ou seja, vazio de significado, sempre enfatizando a teoria e a abstração, a utilização de fórmulas dando maior ênfase na resolução matemática do que em seu significado físico. Neste sentido, tornou-se necessário este trabalho pela necessidade de incorporar o lúdico na prática docente, explorando todos seus benefícios para auxiliar no processo ensinoaprendizagem, onde houve a elaboração de jogos educativos, na intenção de auxiliar professores, considerando o lúdico como uma estratégia para ser usada como estímulo na construção do conhecimento humano e no desenvolvimento de diferentes habilidades operatórias. Foram confeccionados três tipos de jogos lúdicos (Tabuleiro, Dominó e Memória) abordando conceitos de astronomia e astrofísica, para que os professores possam utilizar, tornando assim as aulas mais atrativas, afinal, aprender com prazer torna o resultado melhor, contando com o benefício da interdisciplinaridade dos conteúdos. Como resultado, a socialização de ideias e informações, além da interação entre os alunos, foi incessantemente verificada na execução desta pesquisa. Dessa forma, ao propor atividades diversificadas aos alunos, pôde-se contemplar o aprazimento das turmas ao observar quando foram questionados sobre a importância de usar jogos para aprender física, e também o desejo que outros professores utilizassem jogos em suas respectivas disciplinas.

\section{Metodologia e Material}

Buscando contribuir com os alunos e professores para que compreendam as ciências como produção humana que ocorre em meio social, dessa forma enriquecendo o processo de ensinoaprendizagem (PELIZZARI, 2002) correlacionando a teoria com os conhecimentos observados no dia a dia, pensou-se em confeccionar alguns jogos lúdicos, abordando tópicos de astronomia e astrofísica, o que, conforme observado no trabalho de conclusão de curso da própria autora (STIZ, 2013), são temas que estão ligados ao cotidiano dos alunos de forma direta ou indiretamente, fazendo uma interdisciplinaridade com a grade curricular a ser trabalhada no ano letivo. Como os alunos sempre questionam o pouco e/ou raro uso de materiais alternativos durante as aulas de física, pensou-se em confeccionar três tipos de jogos lúdicos abordando conceitos de astronomia e astrofísica, para que os professores possam utilizar, tornando assim as aulas mais atrativas, com o benefício da interdisciplinaridade dos conteúdos. Foram confeccionados 3 tipos de jogos usando tópicos abordados nas palestras: Tabuleiro, Jogo de Memória e Dominó, onde os mesmos foram impressos em adesivos e aplicados em PVC a fim de obter materiais mais resistentes e ter boa durabilidade. Para confeccionar os jogos, utilizou-se o programa Corel Draw, por ser um software versátil para o desenvolvimento de artes gráficas, além de conter inúmeros recursos gráficos e fácil utilização, a fim de deixar todo o material certo para a impressão e sem perder a qualidade das imagens e textos. Este trabalho foi realizado no IFRO (Instituto Federal de Rondônia) - Campus Ariquemes. No início dessa pesquisa foi aplicado um questionário prévio, a fim de se analisar o conhecimento adquirido ao final das palestras e uso dos jogos e no

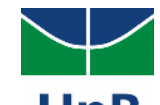


último encontro foi aplicado o questionário final, os jogos e outro questionário a fim de avaliar a utilização dos jogos. Aplicou-se esse trabalho em 6 turmas de $3^{\circ}$ ano do ensino médio. Para a análise dos questionários utilizamos a técnica de amostragem de 100 alunos de um total de 210 .

\section{Resultados e Discussão}

Na figura 1, ao questionar se alguns dos tópicos abordados nos jogos, já foram trabalhados em sala de aula, $60 \%$ responderam que sim, $16 \%$ responderam que não e outros $24 \%$ responderam talvez, sendo que para a última alternativa os alunos consideraram apenas o momento deste trabalho.

Figura 01: Alguns dos tópicos abordados nos jogos, já foram trabalhados em sala de aula?

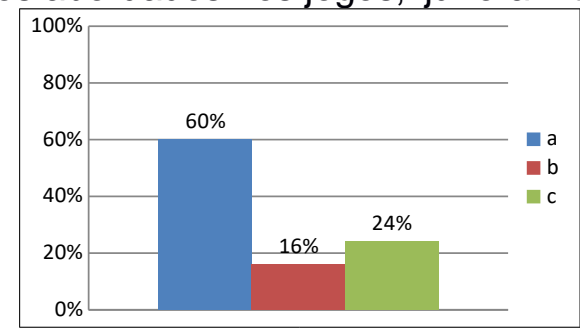

Fonte: autor

Na figura 2, o investigamos o conhecimento prévio dos alunos sobre os assuntos abordados neste trabalho, podemos observar que $68 \%$ já viram em alguma mídia, $4 \%$ nunca viram e outros $28 \%$ talvez, novamente para essa última alternativa, os alunos consideraram as discussões desse trabalho.

Figura 2: Você já tinha visto alguns dos tópicos abordados nos jogos na mídia (jornal, internet...)?

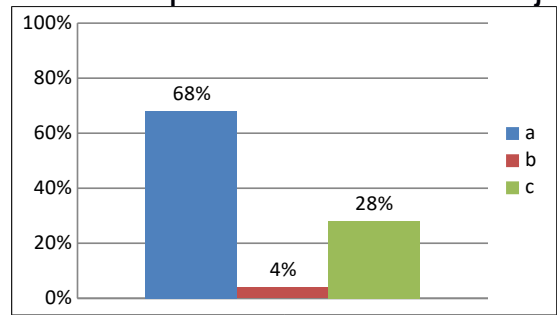

Fonte: autor

\section{Conclusões}

Acredita-se ser necessário atentar-se para a importância da escolha do tema deste trabalho sobre a utilização de jogos como recurso no processo de ensino-aprendizagem de Ciências, mais especificamente no ensino de Física abordando tópicos de astrofísica, pois esse recurso ainda é pouco/raramente usado. A maioria dos trabalhos sobre jogos lúdicos são direcionados à educação infantil e aos anos iniciais do ensino fundamental, transmitindo uma ideia de que a brincadeira está apenas vinculada nessas etapas e não pode fazer parte de outras etapas da educação como, por exemplo, no ensino médio. Por isso o uso de jogos como objeto de aprendizagem merece uma atenção especial para esse nível de educação, por ser um nível ainda carente de propostas pedagógicas.

\section{Referências}

PELIZZARI, A.; KRIEGL, M. L.; BARON, M. P.; FINCK, N. T. L.; DOROCINSKI, S. I. Teoria da Aprendizagem Significativa Segundo Ausubel. Revista PEC, Curitiba, v. 2, n. 1, p. 37-42, jul. 2001 - jul. 2002. 